\title{
PERFORATION OF JEJUNAL ULCER
}

\author{
Kishore K Mankar ${ }^{1}$
}

\section{HOW TO CITE THIS ARTICLE:}

Kishore K Mankar. "Perforation of jejunal ulcer". Journal of Evolution of Medical and Dental Sciences 2013;

Vol. 2, Issue 44, November 04; Page: 8458-8459.

ABSTRACT: Primary Jejunal ulcer is a very rare disease. A 45 year old male presented with symptoms and signs suggestive of G I Perforation. The Diagnosis of jejunal perforation was confirmed following laparotomy.

KEYWORDS: Jejunal Ulcer. Perforation.

CASE REPORT: A 45 years old male patient was admitted to the hospital with severe abdominal pain that had started $18-20$ hours, prior to admission. Abdominal pain was associated with nausea and vomiting.

History of constipation, distension of abdomen was present.

General physical examination revealed an acutely ill man with BP 110 / 60 mm Hg, A Pulse rate of 92 / min with mild increase in the temperature. On systemic examination, the abdomen was tense, tender to palpate, distension and guarding was present. Bowel sounds were absent. All the blood investigations were within normal limits. An erect X-ray abdomen revealed free gas under diaphragm. So with the diagnosis of perforation peritonitis, patient underwent laparotomy.

The peritoneal cavity had approximate $600 \mathrm{ml}$ of free fluid which was aspirated. A perforation was seen in the jejunum about 4" from the duodeno - jejunal junction.

Edge biopsy of the perforation was taken and primary closure of the perforation was done in two layers. Peritoneal toileting was done.

Drains were kept and abdomen closed in layers. The Post operative period was uneventful and the patient was discharged on post operative day 10.

The HPR showed no specific diagnosis responsible for perforation.

DISCUSSION: The term Primary jejunal ulcer relates to an ulcer of the mucosa and deeper layers of the small intestine which usually occurs singly and resembles in its appearance, pathological development, clinical manifestation and complications, the peptic ulcer of the stomach and duodenum.

CONCLUSION: Ulceration of the small bowel does occur apart from the common specific ulcerations. It possesses no definite clinical history, is of uncertain pathology and the etiological processes associated with it remain obscure.

\section{REFERENCES:}

1. Judd of Mayo Clinic - 1921 [Irish Journal of Medical Science by F. J. Morrin ] Irish Journal of Medical Science.

Acute Perforation of Jejunum Secondary to Primary Jejunitis.

By:- Garner Boclaugus C E, Hamelton J E, Ann Surg 1951 Jul, 134 (1) : 131-4 
2. California And Western Medicine 1940, Ulcer of the Jejunum Acute Perforation. By: - George A. Wood, M.D., And Edward Liston, M.D., Palo Alto, 1940 September 53 (3) 130.

3. Perforated Jejunal Ulcer and the Zollinger - Ellison Syndrome By: - Charles G Watson, M.D., Roger V. Moseley, M.D., Brownell Wheeler, M. D. Arch Surg 1968: 96 (2): 274 - 276.

4. Perforation of Jejunal Ulcer into the free Abdominal Cavity By:- Harry A. Singer, M.D., Karl A. Meyer, M.D, Arch Surg 1934 : 29 (2) 248 - 263.
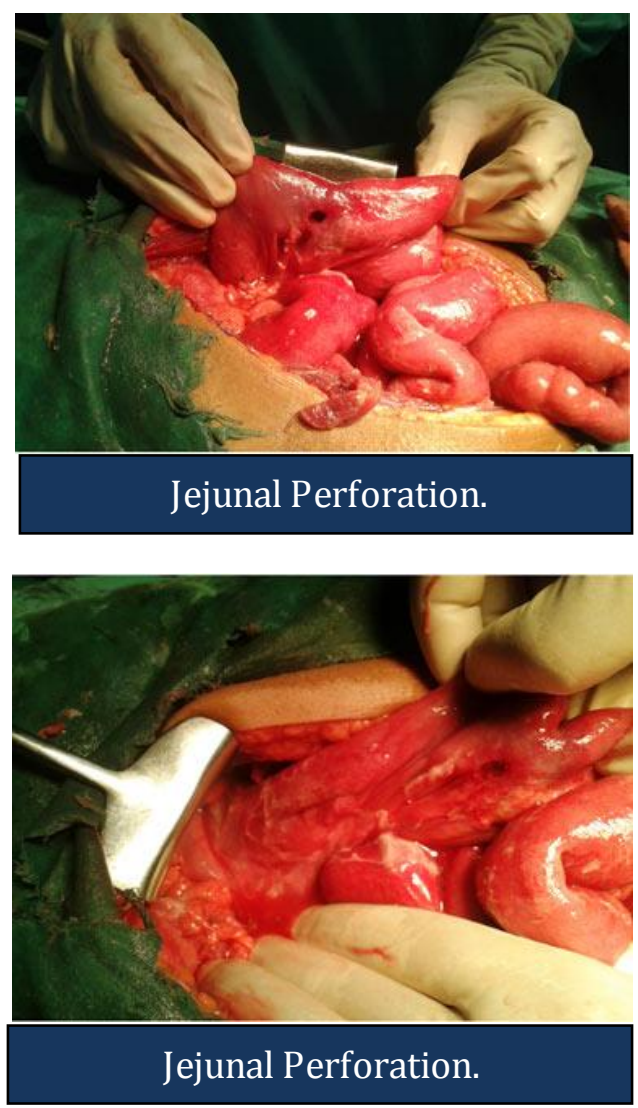

\section{AUTHORS: \\ 1. Kishore K Mankar}

\section{PARTICULARS OF CONTRIBUTORS:}

1. Associate Professor, Shri Renuka Hospital, Gulbarga, Karnataka.
NAME ADDRESS EMAIL ID OF THE CORRESPONDING AUTHOR:

Dr. Kishore K Mankar, Shri Renuka Hos pital, Near Siddeshwar Kalyan Mantap, Old Jewargi Road, Gulbarga - 585102, Karnataka. Email - kimankar@yahoo.in

Date of Submission: 14/10/2013. Date of Peer Review: 15/10/2013. Date of Acceptance: 23/10/2013. Date of Publishing: 29/10/2013 